\title{
Influence of Mechanical Properties of Filling Paste on Overlying Strata Movement and Surface Settlement
}

\author{
Yu-Fei Liu (D, Xin-Hua Wu, Tao Zhu, Xian-Jun Wang, Guo-Yu Zhang, and Zhi-Gang Wang \\ Beijing Tiandi Huatai Mining Management Co. LTD, Beijing 100013, China \\ Correspondence should be addressed to Yu-Fei Liu; lyf6172579@163.com
}

Received 25 November 2021; Revised 20 December 2021; Accepted 22 December 2021; Published 1 March 2022

Academic Editor: Xuepeng Zhang

Copyright (C) 2022 Yu-Fei Liu et al. This is an open access article distributed under the Creative Commons Attribution License, which permits unrestricted use, distribution, and reproduction in any medium, provided the original work is properly cited.

\begin{abstract}
In order to study the relationship between coal seam buried depth and surface subsidence and select appropriate filling materials, taking Donggou coal mine as the engineering geological prototype, through mechanical test and theoretical analysis, this paper studies the distribution characteristics of in-situ stress and the selection of paste filling materials and their proportion test. The influence of different filling strengths on the overburden movement law and surface settlement law of the working face is analyzed. Based on the experimental research and measured research results, the appropriate filling material is selected. The numerical results show that the material ratio scheme 4 can meet the actual needs of surface subsidence in the process of filling mining. At the same time, the surface subsidence value decreases with the increase of coal seam buried depth.
\end{abstract}

\section{Instruction}

The mine filling and mining technology have experienced waste rock dry filling, water sand filling, low concentration tailings cemented filling, and high concentration paste filling. In 1979, Germany took the lead in adopting paste filling mining technology. After the 1980s, paste filling mining was gradually studied and applied in China, and the sedimentation reduction effect was obvious. After the filling body enters the underground goaf, the supporting effect on the roof changes the deformation characteristics of the overlying strata, controls the movement of the roof strata, and reduces the damage of the overlying strata [1].

Chandra et al. [2] obtained some effective methods to prevent concrete slump loss and further proved that the greater the slump, the better the fluidity of concrete. Wallevik et al. [3] established models for the consistency, slump, and expansion of concrete mixture respectively and analyzed the relationship between slump and expansion through calculation and simulation. Zhou et al. [4] deduced a series of formulas and obtained a strong theoretical design method. Compared with the current design method, it avoided the sensitive response to concrete performance caused by determining parameters such as water consumption and sand rate. Lloyd et al. [5] analyzed the effect of ion content in the polymer on durability. By combining field experience and laboratory tests, Cai et al. [6] determined that high foaming materials with a water cement ratio of $1: 0.6$, appropriate high foaming additives, and high foaming materials with a water volume ratio of $1: 30$ are cost-effective in filling and meet the requirements of filling strength. Liu et al. [7] used gypsum, cement, lime, and water glass as adhesives to study the strength of different material ratios. The influencing causative factors of clay strength are cement, gypsum, sodium silicate, and lime. The results show that cement content is the decisive factor, gypsum plays a positive role, and sodium silicate can improve the strength of clay and the fluidity of filling mud.

According to the basic properties of ultrahigh water cut materials, FENG et al. [8] studied the technology of filling goaf with ultrahigh water cut materials, so as to liberate coal resources under buildings. Li et al. [9] discussed the research on the development of alternative goaf filling materials in the laboratory and carried out numerical and field evaluation of their efficiency. Pang et al. [10] used the numerical simulation software FLAC3D to analyze the surface settlement, horizontal displacement, plastic failure range of surrounding rock, and the stress state of the surface and surrounding rock under unfilled and filled conditions. 
In terms of research methods, theoretical analysis can effectively analyze the essence of engineering problems [11-14]. In order to better study the movement law of overlying strata in mining roadway, Chen et al. [15] established a thin plate model of the elastic boundary of the main roof on an elastic foundation. Using the finite difference method, the variation law of the maximum settlement value with the elastic foundation coefficient of coal seam, the elastic foundation coefficient of backfill, Youngs modulus, and Poisson's ratio is calculated and studied. The numerical simulation experiment of geotechnical engineering is a means to simulate the mechanical behavior of rock mass and engineering structure in the process of geotechnical engineering activities and natural environment changes [16-19]. Yan et al. [20] studied the criteria, yield function, and softening parameters of the double yield model. According to the mechanical parameters of the filling body in Xincheng Gold Mine, the simulation parameters of the double yield model are obtained. The filling body in the one-step mining stage is simulated by the FLAC3D numerical simulation method, and the simulation results in the initial stage and later stage are analyzed. The similar material simulation does not directly study the natural phenomenon or process itself but studies the model similar to these natural phenomena or processes. It is a scientific research method closely combining theory and practice. It is an effective method to solve some complex production engineering problems [21-24]. On the basis of a similar simulation test, Wang et al. [25] analyzed the failure characteristics of the roof and the evolution law of support force after filling.

Taking Donggou coal mine as the engineering geological background, this paper selects the reasonable filling material ratio scheme for experimental research and obtains the mechanical properties of filling materials under different material ratio schemes. Using the method of numerical simulation, the characteristics of surface subsidence under different material ratios are analyzed, and the relationship between surface subsidence, buried depth, and mechanical characteristics of filling materials is analyzed.

\section{Overview of Engineering Geology}

2.1. Overview of Research Target Project. Donggou coal mine is located in Hutubi County, Xinjiang Autonomous Region, China, $85 \mathrm{~km}$ away from Urumqi. The geotectonic position of the mining area belongs to the middle of the western section of the Urumqi Piedmont depression on the southern margin of the Junggar Basin, and is located on the Santun River ningjiahe monoclinal structural belt. The fault structures in the mining area are relatively developed, mostly distributed outside the minefield. Shiti Gangou reverse fault F6 and parallel F7 thrust fault and two small NE trending thrust faults are developed in the middle of the area to the south of the minefield. Controlled by the regional monoclinal structure, the minefield is generally a monoclinal structure gently inclined to the north, with a dip of $10^{\circ}-25^{\circ}$ and an inclination of $10^{\circ}-15^{\circ}$. It belongs to a gently inclined coal seam. The strata exposed in the well field are Sangonghe Formation (J1s) of Lower Jurassic, Xishanyao Formation
(J2x) of Middle Jurassic, Toutunhe Formation (J2t), quaternary upper Pleistocene Holocene flood alluvium (Q3-4pal), and quaternary Holocene diluvium (Q-4 dl).

This study mainly studies that the coal seam is one of the main mining coal seams. The lowest elevation controlled by the project is $1107.43 \mathrm{~m}$, the highest elevation is $1573.00 \mathrm{~m}$, and the buried depth is $175.23-549.31 \mathrm{~m}$. The minability index of the coal seam area is $100 \%$, with wide coverage and a large drop. (Figure 1)

2.2. In Situ Stress Test. The in-situ stress testing equipment adopts a hollow inclusion stress meter composed of 12 resistance strain gauges. Paste three groups of strain flowers (each group has four strain gauges) at an interval of $120^{\circ}$ along the circumference of the epoxy resin cylinder. The in-situ stress test point is located in the B2 coal seam to avoid complex geological structures. The number of measuring points is 9 . The test results are shown in Table 1. The maximum horizontal stress, minimum horizontal stress, and vertical stress increase with the increase of depth and show a nearly linear growth relationship. The maximum horizontal stress of all measuring points is greater than the vertical stress, $\sigma_{\mathrm{H}}$ indicating the maximum principal stress, $\sigma_{\mathrm{h}}$ minimum principal stress, and $\sigma_{\mathrm{v}}$ vertical stress (intermediate principal stress).

$$
\begin{aligned}
\sigma_{\mathrm{H}} & =0.0398 H-1.7632, \\
\sigma_{\mathrm{h}} & =0.0316 H-7.4574, \\
\sigma_{\mathrm{v}} & =0.0464 H-1.5134 .
\end{aligned}
$$

\section{Selection of Raw Materials for Filling and Its Proportioning Test}

The raw materials for filling are coal gangue and fly ash, in which the coal gangue needs to be crushed (the particle size is controlled within $25 \mathrm{~mm}$ ), the SL paste cement developed by the China University of Mining and Technology (taking the water quenched slag of steel plant as the base material), and the mixing water adopts bedrock aquifer water, as shown in Figure 2. As waste emissions, coal gangue occupies a lot of lands and pollutes the environment. Coal gangue is used as filling material to reduce the pollution of gangue to the environment. Fly ash is a solid waste discharged from coal-fired power plants. The application of fly ash in coal mine filling will open up a new way for the utilization of fly ash. In the experiment, the maximum particle size of coal gangue is controlled within $25 \mathrm{~mm}$, and the amount of fly ash is fixed at $400 \mathrm{~kg} / \mathrm{m}^{3}$ after the optimization experiment.

The relationship between the mass concentration of gangue and slump is shown in Figure 2. When the mass concentration of gangue is $67.5 \%$, the slump height is $24 \mathrm{~cm}$. When the mass concentration is $69 \%$, the slump height is $22 \mathrm{~cm}$. When the mass concentration rises to $70.5 \%$, the slump height is $24.5 \mathrm{~cm}$. When the mass concentration is greater than $70.5 \%$, the slump height tends to slow down with the increase of mass concentration. Therefore, choosing the gangue concentration of $70.5 \%$ can not only increase the amount of gangue but also meet the construction needs (Figure 3). 

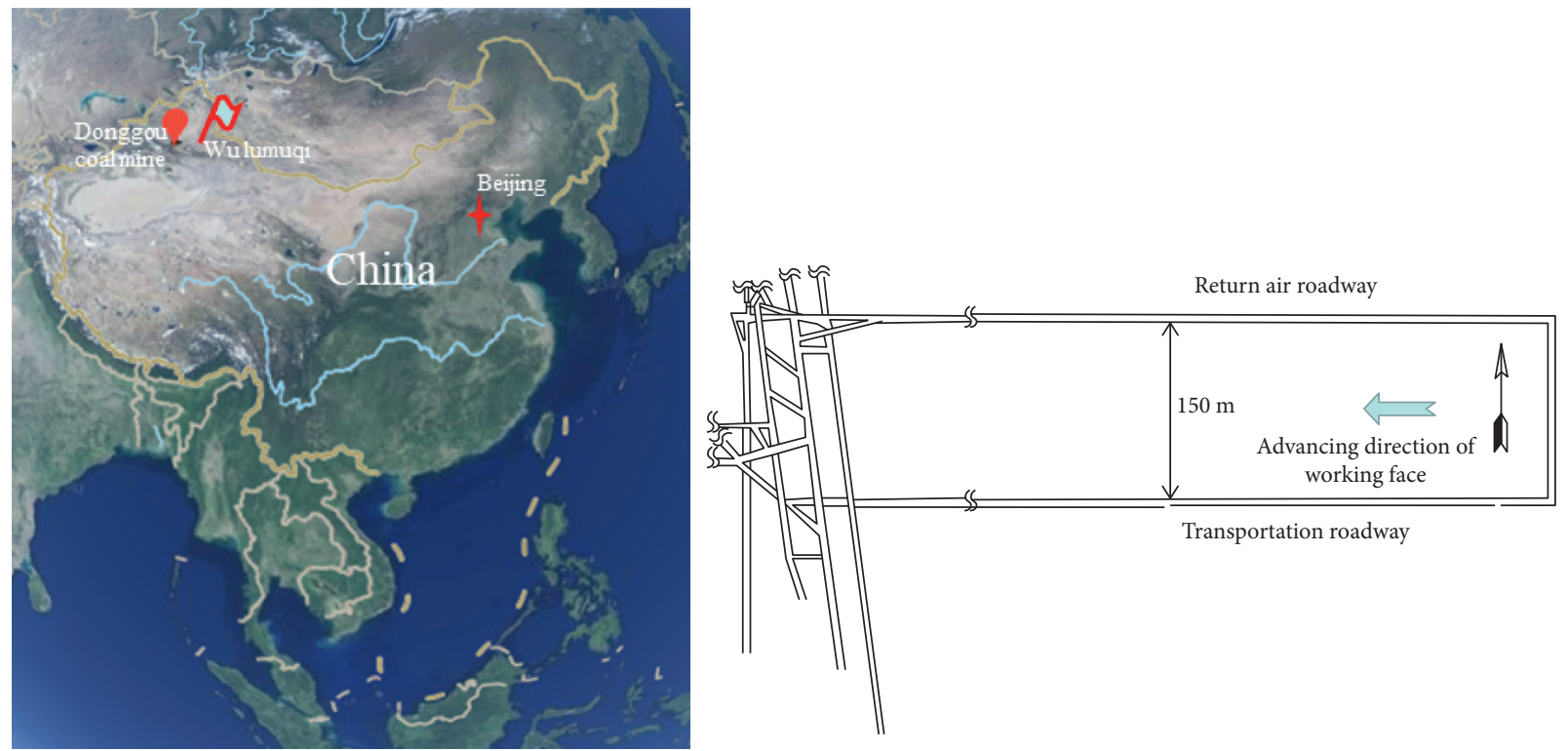

FIGURE 1: Research target location and working face layout.

TABLE 1: In situ stress test results.

\begin{tabular}{|c|c|c|c|c|c|c|c|c|c|}
\hline \multirow{2}{*}{ Depth/m } & \multicolumn{3}{|c|}{ Maximum principal stress $\sigma_{1}$} & \multicolumn{3}{|c|}{ Intermediate principal stress $\sigma_{2}$} & \multicolumn{3}{|c|}{ Minimum principal stress $\sigma_{3}$} \\
\hline & Stress $\mathrm{MPa}$ & Direction $^{\circ}$ & Dip angle ${ }^{\circ}$ & Stress $\mathrm{MPa}$ & Direction $^{\circ}$ & Dip angle ${ }^{\circ}$ & Stress $\mathrm{MPa}$ & Direction $^{\circ}$ & Dip angle ${ }^{\circ}$ \\
\hline 205.17 & 7.01 & 100.65 & -3.05 & 4.31 & 268.26 & -35.40 & 3.51 & 185.09 & -45.08 \\
\hline 243.78 & 7.70 & 118.49 & -13.62 & 5.46 & 16.40 & -50.37 & 3.96 & 207.05 & -26.35 \\
\hline 274.92 & 10.86 & 126.20 & 21.33 & 6.72 & 264.23 & 57.27 & 5.00 & 202.83 & -9.14 \\
\hline 285.49 & 12.24 & 138.57 & 25.72 & 6.84 & 76.19 & -29.04 & 6.55 & 190.64 & -39.44 \\
\hline 354.38 & 15.80 & 110.42 & -5.11 & 7.81 & 24.83 & -39.17 & 6.38 & 196.29 & -40.96 \\
\hline 309.34 & 11.95 & 214.57 & 17.30 & 6.55 & 109.98 & 46.70 & 4.92 & 144.84 & -27.96 \\
\hline 384.21 & 13.10 & 202.83 & 0.45 & 7.37 & -38.36 & 54.76 & 6.01 & 121.90 & 25.90 \\
\hline 557.83 & 22.18 & 209.29 & -12.82 & 13.79 & 48.04 & -67.85 & 12.06 & 128.62 & 0.02 \\
\hline 551.92 & 20.97 & 110.87 & -6.18 & 16.49 & 33.52 & 25.01 & 13.79 & 180.16 & 54.76 \\
\hline
\end{tabular}

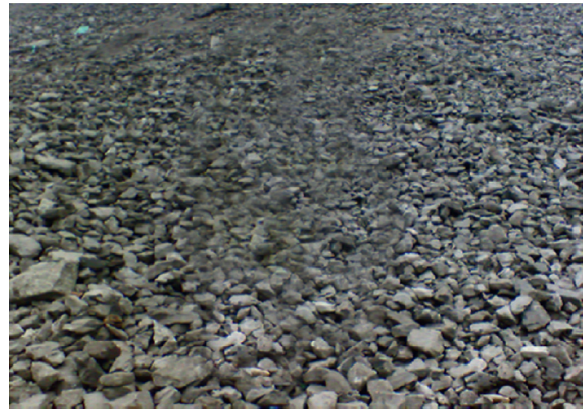

(a)

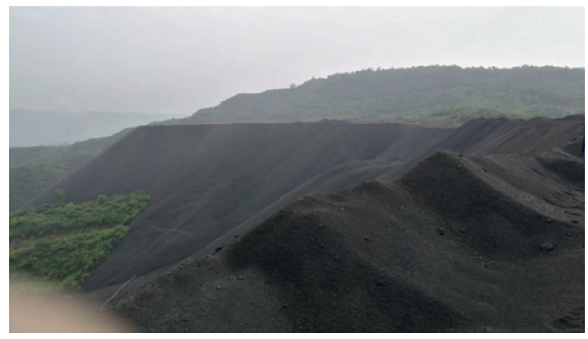

(c)

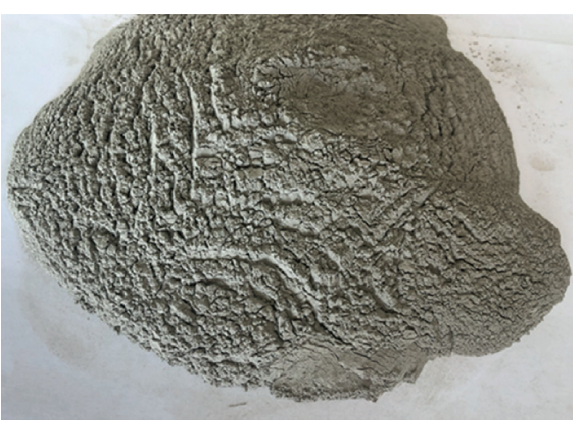

(b)

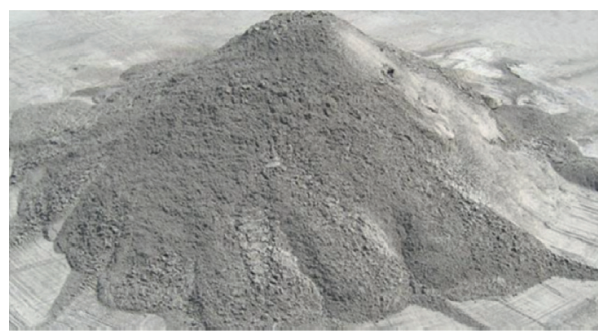

(d)

Figure 2: Filling material. (a) Gangue, (b) fly ash, (c) steel mill quenched slag, and (d) cementitious material. 


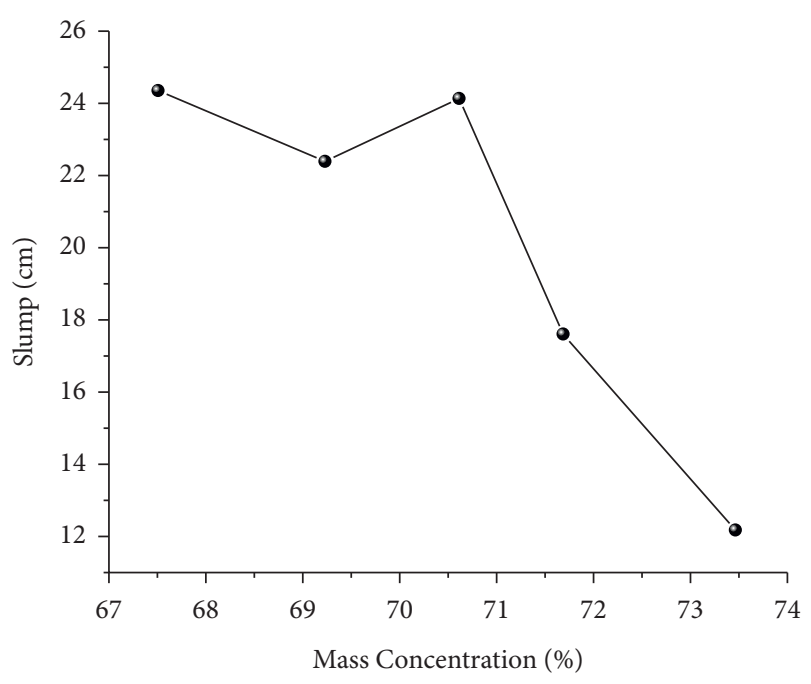

Figure 3: Relationship between filling body slump and mass concentration.

The natural particle size gradation of coal gangue changes greatly, which has a great impact on the fluidity and strength of the filling. Therefore, it is necessary to crush the coal gangue to obtain the required gradation. On the premise of meeting the paste ratio, the particle size grading of broken coal gangue mainly considers two specifications are as follows: gangue with particle size less than $5 \mathrm{~mm}$ and gangue with the particle size of 5-25 $\mathrm{mm}$. Through the test of these two specifications of gangue, the ratio is optimized. The expansion degree of concrete is related to its fluidity. The greater the fluidity, the greater the expansion degree. Figure 4 shows the variation characteristics of the expansion degree of filling under different gradations based on the dosage of paste binder of $100 \mathrm{~kg} / \mathrm{m}^{3}$. When the gangue with particle size less than $5 \mathrm{~mm}$ accounts for $37 \%$, the expansion degree is $630 \mathrm{~mm}$. When the gangue with particle size less than $5 \mathrm{~mm}$ accounts for $41 \%$, the expansion degree drops sharply to $560 \mathrm{~mm}$. When its proportion is $43 \%$, the expansion increases to $580 \mathrm{~mm}$. When the ratio is $46 \%$, the expansion is $550 \mathrm{~mm}$.

Unconfined compressive strength tests were carried out on fillings with different gangue grading and curing ages. The results are shown in Figure 5. It can be seen that the strength of filling the body with four mix proportions increases gradually with the increase of curing age. When the gangue with particle size less than $5 \mathrm{~mm}$ accounts for $41 \%$, the strength is the largest, and the strength reaches $1.3 \mathrm{MPa}$ at $28 \mathrm{~d}$ age. The strength range of all samples at $28 \mathrm{~d}$ age is $1-1.3 \mathrm{MPa}$, and the strength meets the engineering strength requirements (the strength at $28 \mathrm{~d}$ age is $2 \sim 4 \mathrm{MPa}$ ).

Table 2 shows the strength characteristics of the filling body under different material ratios. At the age of $8 \mathrm{~h}$, the strength of the filling body under each mix proportion is $0-1.25 \mathrm{MPa}$. At the age of $1 \mathrm{~d}$, the strength of the filling body under each mix proportion is $0.1-1.62 \mathrm{MPa}$. At the age of $3 \mathrm{~d}$, the strength of the filling body under each mix proportion is $0.21-2.27 \mathrm{MPa}$. At the age of 7 days, the strength of the filling body under each mix proportion is $0.3-2.56 \mathrm{MPa}$.

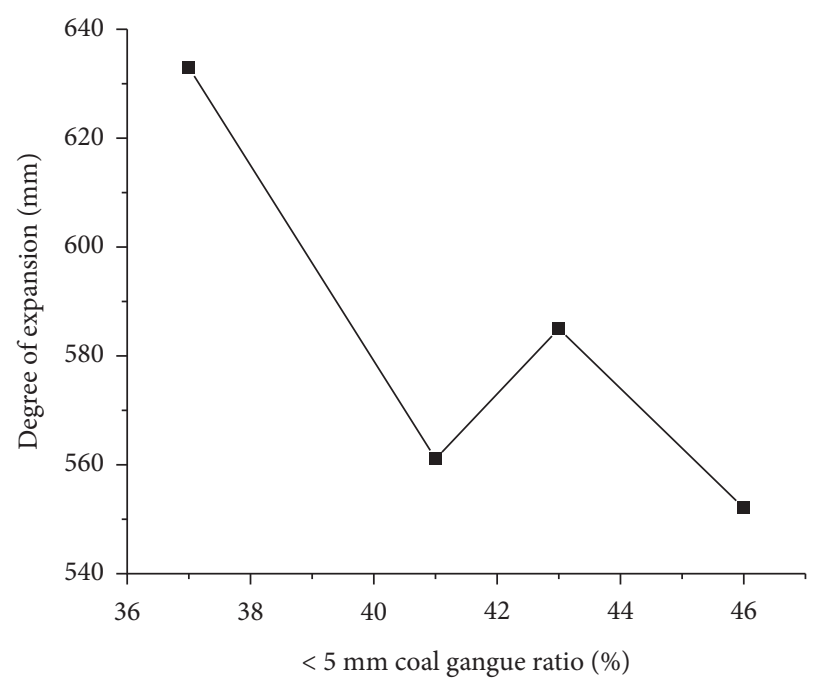

FIgURE 4: Expansion degree of filling under different particle gradations of coal gangue.

At the age of 28 days, the strength of the filling body under each mix proportion is $0.57-2.95 \mathrm{MPa}$. The proportion of cement has a great influence on the strength of backfill. According to the above preliminary proportioning experiment and the technical requirements of paste filling materials, the proportioning scheme that can meet the requirements of filling engineering is selected, and the influence of paste with different characteristics on filling engineering is analyzed and discussed in detail.

\section{Rock Movement Characteristics and Surface Subsidence Law under Different Paste Strengths}

4.1. Establishment of Numerical Calculation Model. In the process of filling mining, the change of filling strength has different effects on the surface and overburden [26]. The characteristics of rock movement and surface subsidence under different filling strengths should be studied. The main purpose of the numerical simulation is to compare the surface subsidence of caving mining and filling mining through numerical calculation; The rock movement characteristics and surface subsidence law under different filling strengths are simulated.

The target working face is flat, with a ground elevation of $+38.03 \sim+39.69 \mathrm{~m}$ and an average elevation of $+38.85 \mathrm{~m}$. The floor elevation is $-354.56 \sim-464.30 \mathrm{~m}$, the buried depth of the coal seam is $393.39-502.80 \mathrm{~m}$, with an average of $440.15 \mathrm{~m}$, the thickness of the coal seam is $1.67-3.36 \mathrm{~m}$, with an average thickness of $2.74 \mathrm{~m}$, and the dip angle of the coal seam is generally $3^{\circ}-11^{\circ}$, with an average of $6^{\circ}$. The overlying bedrock is $159.67-247.17 \mathrm{~m}$ thick, with an average of $191.98 \mathrm{~m}$. The thickness of Quaternary topsoil is $220.82-283.37 \mathrm{~m}$, with an average of $245.43 \mathrm{~m}$. It is mainly composed of clay, sandy clay, clayey sand, sand, and gravel, belonging to river lake facies deposition. The direct roof and main roof are dominated by siltstone and medium sandstone, with a thickness of 7.3-16.97 m, mudstone clay is seen 


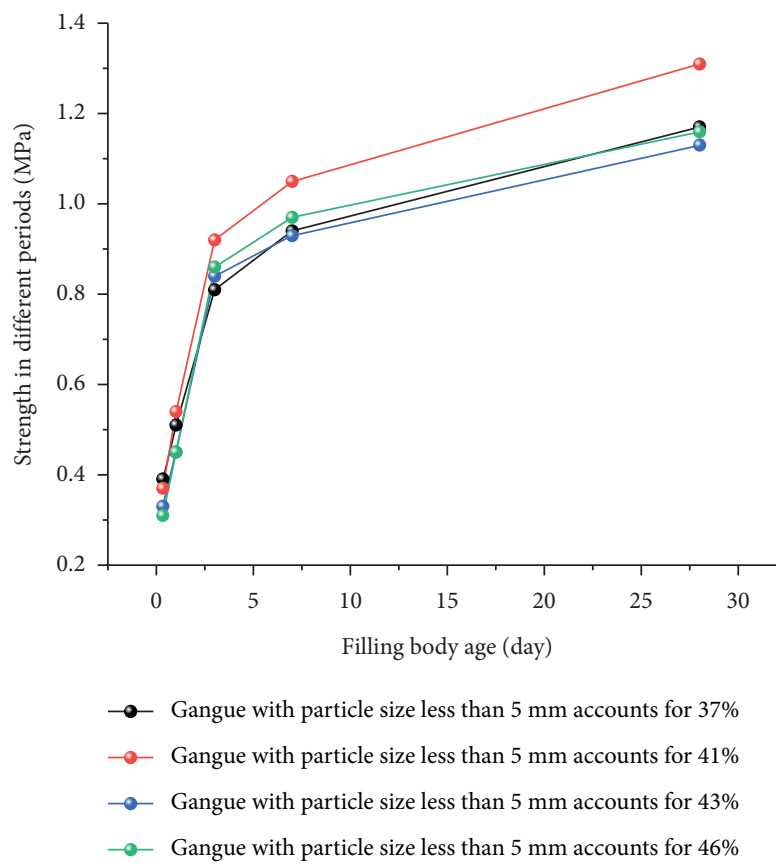

FIGURE 5: Effect of the particle size distribution of coal gangue on strength of filling body.

TABLE 2: Result of the introduction test for filling material matching age-intensity.

\begin{tabular}{|c|c|c|c|c|c|c|c|c|c|}
\hline \multirow{2}{*}{ Experimental scheme } & \multicolumn{4}{|c|}{ Material ratio $\mathrm{kg} / \mathrm{m}^{3}$} & \multicolumn{5}{|c|}{ Uniaxial compressive strength/MPa } \\
\hline & Cementitious material & Fly ash & Gangue & Water & $8 \mathrm{~h}$ & $1 \mathrm{~d}$ & $3 \mathrm{~d}$ & $7 \mathrm{~d}$ & $28 \mathrm{~d}$ \\
\hline 1 & 100 & 400 & 701 & 489 & 0.00 & 0.10 & 0.21 & 0.30 & 0.57 \\
\hline 2 & 120 & 400 & 712 & 542 & 0.12 & 0.12 & 0.33 & 0.42 & 0.77 \\
\hline 3 & 150 & 400 & 719 & 502 & 0.14 & 0.18 & 0.53 & 0.69 & 1.19 \\
\hline 4 & 100 & 400 & 1066 & 402 & 0.28 & 0.33 & 0.60 & 0.90 & 1.22 \\
\hline 5 & 100 & 400 & 1162 & 385 & 0.19 & 0.21 & 0.41 & 0.49 & 0.69 \\
\hline 6 & 60 & 572 & 1493 & 521 & 0.22 & 0.40 & 0.50 & 0.63 & 0.64 \\
\hline 7 & 80 & 572 & 1320 & 510 & 0.40 & 0.71 & 0.88 & 1.09 & 1.24 \\
\hline 8 & 100 & 572 & 1184 & 488 & 0.61 & 0.91 & 1.12 & 1.54 & 1.69 \\
\hline 9 & 150 & 572 & 1222 & 529 & 1.25 & 1.62 & 2.27 & 2.56 & 2.95 \\
\hline
\end{tabular}

locally, the pseudo roof is $0.8-1.4 \mathrm{~m}$ thick, and fractures are developed. The numerical calculation model is shown in Figure 6.

3DEC (3 Dimension Distinct Element Code) is a threedimensional discrete element program for dealing with discontinuous media. It is used to simulate the response of discontinuous media under static or dynamic load. Discontinuous media are represented by discrete block aggregates. The discontinuous surface is treated as the boundary between blocks, allowing large displacement and rotation of blocks along the discontinuous surface. A block can be a rigid body or a deformable body [27]. The deformed block is divided into finite element meshes, and each element is linear or nonlinear according to the given "stress-strain" criterion. The normal and tangential relative motion of the discontinuity is also controlled by the linear or nonlinear "force-displacement" relationship.

The dip angle of the target coal seam is small, so the horizontal coal seam is considered in the actual numerical simulation calculation. According to the needs of simulation, the stratigraphic conditions of mine are simplified are as follows: the coal seam floor is fine-grained sandstone, and the thickness is $40 \mathrm{~m}$; The thickness of siltstone is $2 \mathrm{~m}$; The thickness of coal seam is taken as $2.6 \mathrm{~m}$; The thickness of the medium graded sandstone of the roof is $11.4 \mathrm{~m}$; The thickness of siltstone is $7.4 \mathrm{~m}$; The thickness of medium-grained sandstone is $4.2 \mathrm{~m}$ and that of siltstone is $10.8 \mathrm{~m}$. According to the mechanical properties of coal and rock mass, the "Mohr-Coulomb" criterion is adopted for the constitutive relationship of coal and rock mass, and the joint surface contacts Coulomb slip criterion is adopted for joints. The values of rock mass and structural plane are shown in Tables 3 and 4 .

4.2. Analysis of Calculation Results. As shown in Figure 7, it shows the comparative analysis of roof movement law between complete caving mining and filling mining. As shown in Figure 7(a), without filling, the direct roof completely falls, and the roof collapse distance is up to $3 \mathrm{~m}$. The surface 


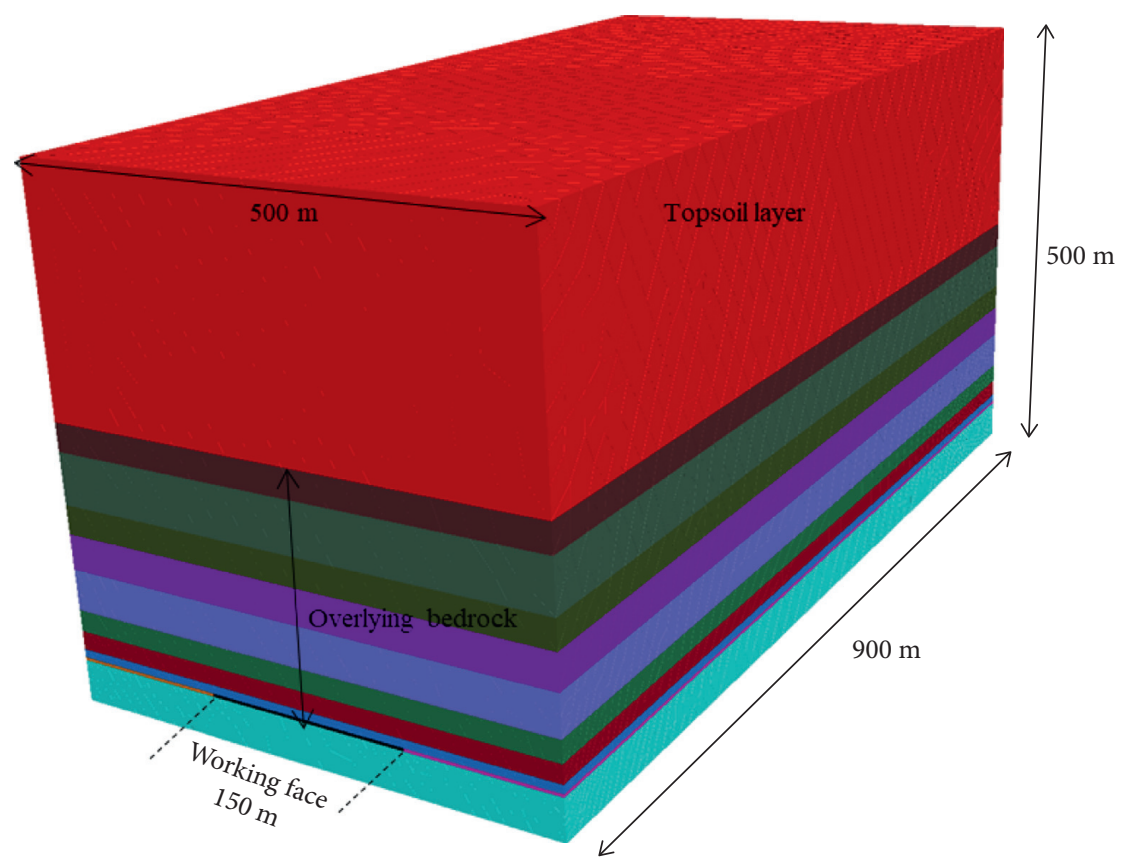

FIgURE 6: Numerical calculation model.

TABLE 3: Mechanical parameters of coal and rock.

\begin{tabular}{|c|c|c|c|c|c|}
\hline Rock stratum & Density $\left(\mathrm{kgm}^{3}\right)$ & Bulk modulus (GPa) & Shear modulus (GPa) & Internal friction angle $\left({ }^{\circ}\right)$ & Cohesion $(\mathrm{MPa})$ \\
\hline Quaternary topsoil & 2460.1 & 6.6 & 4.9 & 14.3 & 0.5 \\
\hline Medium grained sandstone & 2668.4 & 36.9 & 29.9 & 33.4 & 1.6 \\
\hline Siltstone & 2446.4 & 44.3 & 42.9 & 50.1 & 2.0 \\
\hline Fine grained sandstone & 2758.3 & 40.0 & 41.3 & 49.7 & 1.5 \\
\hline Coal seam & 1565.7 & 2.4 & 1.1 & 31.3 & 1.3 \\
\hline
\end{tabular}

TABle 4: Mechanical parameters of coal and rock joints.

\begin{tabular}{lccccc}
\hline Rock stratum & $\begin{array}{c}\text { Normal stiffness } \\
(\mathrm{Gpa})\end{array}$ & $\begin{array}{c}\text { Shear stiffness } \\
(\mathrm{Gpa})\end{array}$ & $\begin{array}{c}\text { Cohesion } \\
(\mathrm{Mpa})\end{array}$ & $\begin{array}{c}\text { Internal friction } \\
\text { angle }\left(^{\circ}\right)\end{array}$ & $\begin{array}{c}\text { Tensile strength } \\
(\mathrm{Mpa})\end{array}$ \\
\hline Quaternary topsoil & 1.04 & 0.94 & 0.00 & 18.19 & 0.00 \\
Medium grained sandstone & 3.13 & 2.06 & 0.51 & 26.57 & 2.72 \\
Siltstone & 4.03 & 4.20 & 0.57 & 6.20 & 7.78 \\
Fine grained sandstone & 4.69 & 3.25 & 0.38 & 2.93 & 3.47 \\
Coal seam & 3.26 & 1.03 & 0.16 & 20.88 \\
\hline
\end{tabular}

subsidence gradually decreases from the corresponding position in the center of the working face to both sides, and the maximum surface subsidence can reach $0.73 \mathrm{~m}$. As shown in Figure 7(b), when the material ratio is scheme 4, the roof deformation is $0.12 \mathrm{~m}$, the maximum surface subsidence is $0.081 \mathrm{~m}$, and the surface subsidence law is also the maximum in the center and gradually decreases to both sides.

As shown in Figure 8, it shows the subsidence of coal seam roof under different material ratios. The maximum deformation is $123 \mathrm{~mm}$, which is scheme 1 . The minimum deformation is $47 \mathrm{~mm}$, which is scheme 9 . According to the engineering requirements, scheme 3 , scheme 4 , scheme 7 , scheme 8 , and scheme 9 can meet the requirements. Among the above options, the minimum amount of cementitious material in is scheme 7 with $80 \mathrm{~kg} / \mathrm{m} 3$, and the minimum amount of fly ash in schemes 3 and 4 is $400 \mathrm{~kg} / \mathrm{m} 3$.

As shown in Figure 9, it shows the surface settlement under different material ratios. The maximum value of the surface settlement is $98 \mathrm{~mm}$ and the minimum value is $38 \mathrm{~mm}$. The maximum settlement coefficient refers to the interpolation between surface settlement and roof subsidence, and the ratio to roof subsidence. The results of each scheme are shown in Figure 10, with the maximum value of 0.24 and the minimum value of 0.06. According to the research objective, the surface subsidence should be controlled within $80 \mathrm{~mm}$. Considering the project cost, scheme 4 in the material ratio is selected. 


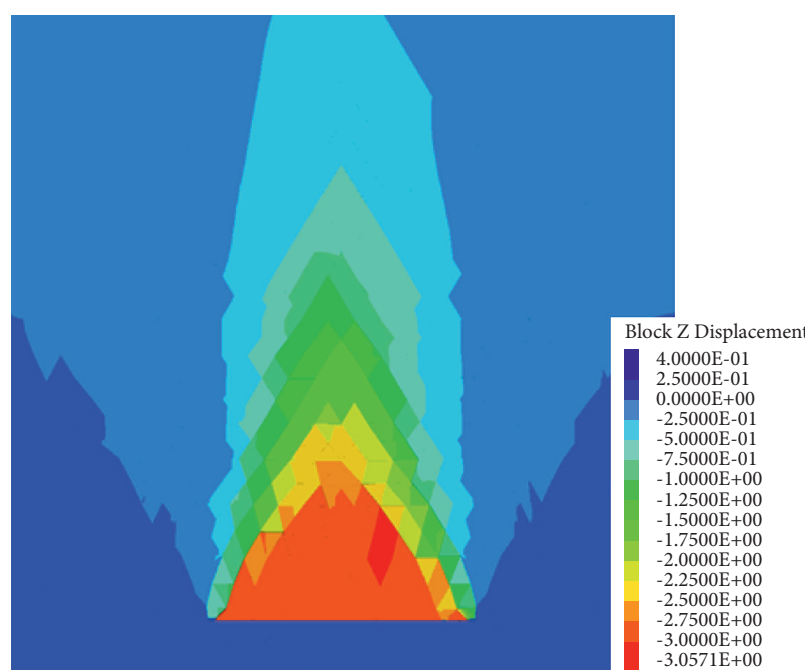

(a)

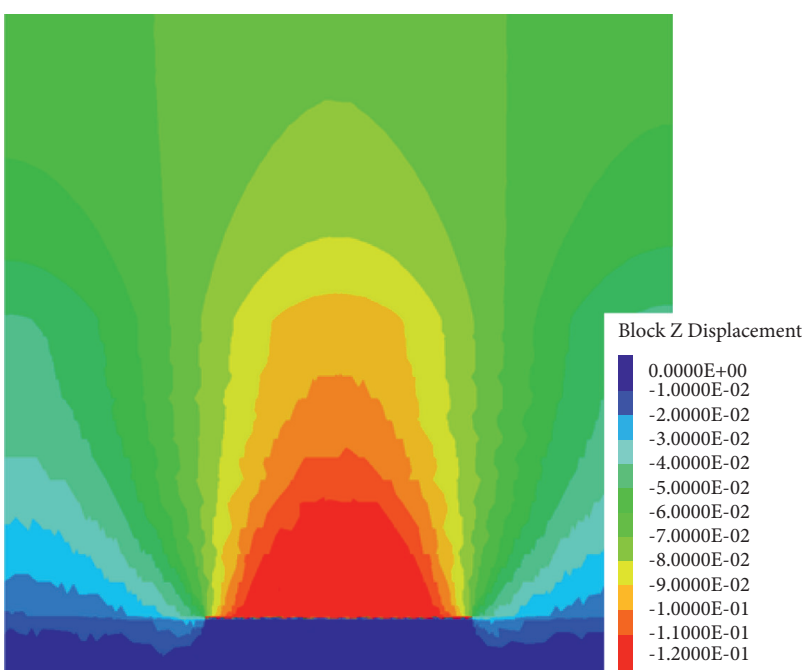

(b)

FIGURE 7: Deformation characteristics of the roof under unfilled mining and filling mining. (a) Roof movement and ground subsidence without filling and (b) roof movement and ground subsidence without filling scheme 4.

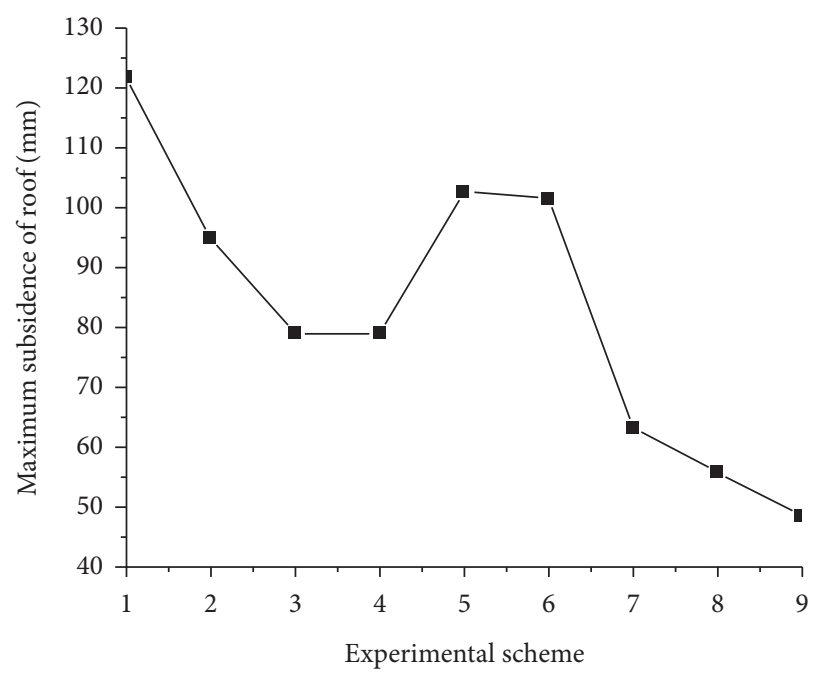

FIGURE 8: Influence of filling strength on roof subsidence.

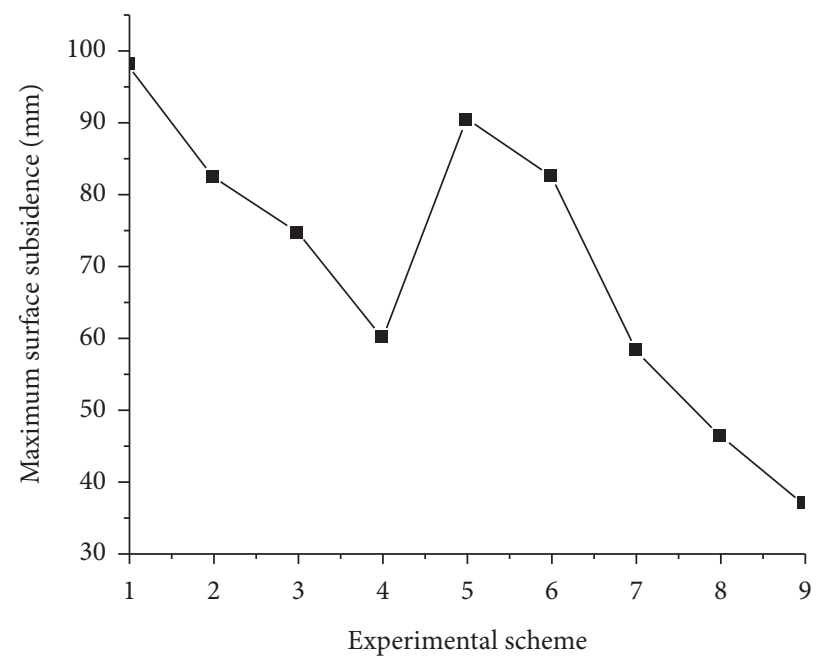

Figure 9: Influence of filling strength on land subsidence. 


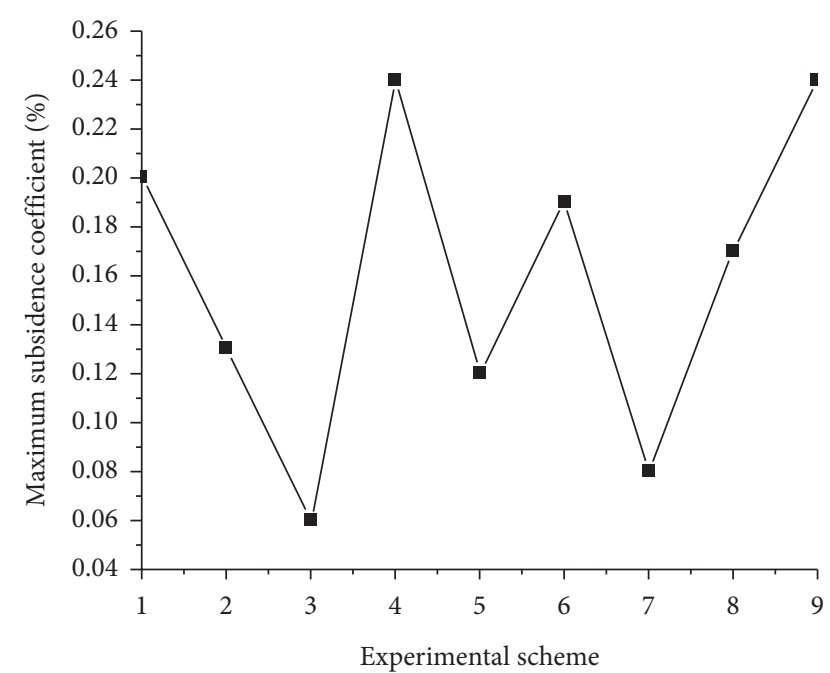

Figure 10: Effect of filling strength on maximum subsidence coefficient.

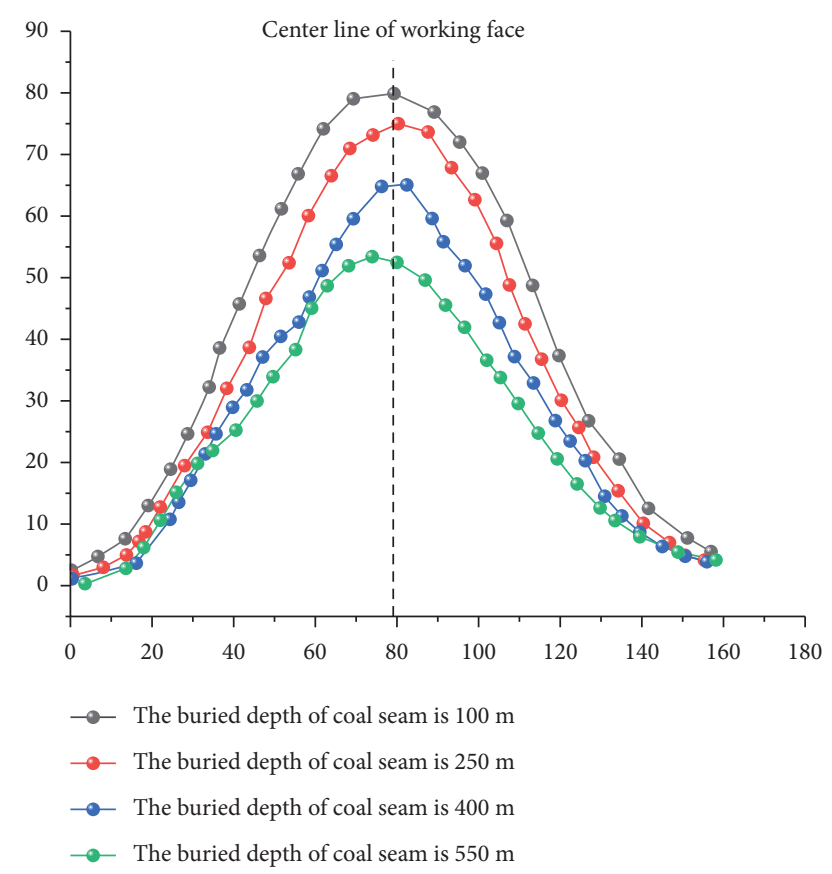

FIGURE 11: Law of surface subsidence under the influence of different buried depths.

4.3. Surface Subsidence Law under Different Buried Depths. Under the proportioning scheme with filling material of 4 , when the filling rate, advancing distance, and other geological conditions are the same, and the buried depths are $100 \mathrm{~m}, 250 \mathrm{~m}, 400 \mathrm{~m}$, and $550 \mathrm{~m}$ respectively, the surface subsidence parameters are shown in Figure 11.

It can be seen from the figure that the affected area is relatively consistent for the four buried depths. However, the maximum subsidence, inclination, curvature, horizontal movement, and horizontal deformation parameters at the buried depth of $100 \mathrm{~m}$ are greater than those at the buried depth of $550 \mathrm{~m}$. With the increase of coal seam buried depth, the surface deformation tends to slow down. When the buried depth is $250 \mathrm{~m}$, the surface settlement value is about 1.07 times that of $100 \mathrm{~m}$. When the buried depth is $400 \mathrm{~m}$, the surface settlement value is about 1.27 times that of $100 \mathrm{~m}$. When the buried depth is $550 \mathrm{~m}$, the surface settlement value is about 1.6 times that of $100 \mathrm{~m}$.

\section{Conclusion}

The research shows that filling mining can effectively control surface subsidence, and different material ratios have a great influence on the strength of the filling body. Filling strength has a decisive influence on surface subsidence. Through laboratory tests and numerical simulation, a more reasonable filling parameter is selected, and the influence of coal seam buried depth on surface subsidence under this filling parameter is analyzed. The specific conclusions are as follows:

(1) The relationship between the mass concentration of different gangue gypsum and slump is experimentally studied. The gangue concentration is $70.5 \%$, which can increase the amount of gangue and meet the construction needs. Different coal gangue gradations were tested to optimize its ratio. The strength characteristics of backfill under different material ratios were studied. According to the technical requirements of paste filling materials, the proportion scheme that can meet the requirements of filling engineering is selected.

(2) Through numerical calculation, the surface subsidence of caving mining and filling mining is compared and studied; the rock movement characteristics and surface subsidence law under different filling strengths are simulated. The appropriate paste proportion scheme was selected.

(3) The influence of different buried depths on surface subsidence under filling mining conditions is analyzed. The maximum horizontal stress, minimum horizontal stress, and vertical stress increase with the increase of depth. The research shows that the surface subsidence will decrease with the increase of buried depth.

\section{Data Availability}

The data used to support the findings of the study are available within the article.

\section{Conflicts of Interest}

The authors declare that there are no conflicts of interest.

\section{Acknowledgments}

This work was financially supported by Tiandi Huatai Independent Science and Technology Innovation Fund Project (Nos. TDHTKY2021009 and TDHTKY2021005) and Science and Technology Innovation and Entrepreneurship 
Fund Project of Tiandi Technology Co., LTD (No. 2020-TDMS007).

\section{References}

[1] Z. Wang, W. Yu, and F. Liu, "The materialization characteristics and ratio of a new soil paste filling material," $A d$ vances in Civil Engineering, vol. 2020, Article ID 6645494, 2020.

[2] S. Chandra and J. Bjornstrom, "Influence of superplasticizer type and dosage on the slump loss of Portland cement mortars-Part II," Cement and Concrete Research, vol. 32, no. 10, pp. 1613-1619, 2002.

[3] J. E. Wallevik, "Relationship between the Bingham parameters and slump," Cement and Concrete Research, vol. 36, no. 7, pp. 1214-1221, 2006.

[4] N. Zhou, H. Ma, S. Ouyang, D. Germain, and T. Hou, "Influential factors in transportation and mechanical properties of aeolian sand-based cemented filling material," Minerals, vol. 9, no. 2, p. 116, 2019.

[5] R. R. Lloyd, J. L. Provis, and J. S. J. Van Deventer, "Pore solution composition and alkali diffusion in inorganic polymer cement," Cement and Concrete Research, vol. 40, no. 9, pp. 1386-1392, 2010.

[6] W. Cai, Z. Chang, D. Zhang, X. Wang, W. Cao, and Y. Zhou, "Roof filling control technology and application to mine roadway damage in small pit goaf," International Journal of Mining Science and Technology, vol. 29, no. 3, pp. 477-482, 2019.

[7] Z. Liu, W. Dang, Q. Liu, G. Chen, and K. Peng, "Optimization of clay material mixture ratio and filling process in gypsum mine goaf," International Journal of Mining Science and Technology, vol. 23, no. 3, pp. 337-342, 2013.

[8] G. Feng, C. Sun, C. Wang, and Z. Zhou, "Research on goaf filling methods with super high-water material," Journal of China Coal Society, vol. 35, no. 12, pp. 1963-1968, 2010.

[9] J. Li, Z. Q. Yin, Y. Li, and C. M. Li, "Waste rock filling in fully mechanized coal mining for goaf-side entry retaining in thin coal seam," Arabian Journal of Geosciences, vol. 12, no. 16, pp. 1-11, 2019.

[10] L. Pang, W. Liu, Q. Zheng, Y. Du, X. Meng, and X. Lial, "Evaluation and analysis of metal mine filling based on numerical simulation and actual measurement," Environmental Earth Sciences, vol. 80, no. 16, pp. 1-24, 2021.

[11] C. Zhu, M. C. He, Z. G. Tao, Q. X. Meng, and X. H. Zhang, "Recognition and prevention of rockfall vulnerable area in open-pit mines based on slope stability analysis," Geomechanics and Engineering, vol. 26, no. 5, pp. 441-452, 2021.

[12] C. Zhu, Y. Lin, and G. Feng, "Influence of temperature on quantification of mesocracks: implications for physical properties of fine-grained granite," Lithosphere, vol. 2021, Article ID 7824057, 2021.

[13] G. Li, Y. Hu, and S. Tian, "Analysis of deformation control mechanism of prestressed anchor on jointed soft rock in large cross-section tunnel," Bulletin of Engineering Geology and the Environment, vol. 80, pp. 1-15, 2021.

[14] X. Li, K. Peng, J. Peng, and D. Hou, "Experimental investigation of cyclic wetting-drying effect on mechanical behavior of a medium-grained sandstone," Engineering Geology, vol. 293, Article ID 106335, 2021.

[15] D. Chen, X. Wu, S. Xie et al., "Study on the Thin Plate Model with Elastic Foundation Boundary of Overlying Strata for Backfill mining," Mathematical Problems in Engineering, vol. 2020, Article ID 8906091, 2020.
[16] X. Li, K. Peng, J. Peng, and H. Xu, "Effect of cyclic wettingdrying treatment on strength and failure behavior of two quartz-rich sandstones under direct shear," Rock Mechanics and Rock Engineering, vol. 54, no. 11, pp. 5953-5960, 2021.

[17] M. Z. Gao, J. Xie, Y. N. Gao et al., "Mechanical behavior of coal under different mining rates: a case study from laboratory experiments to field testing," International Journal of Mining Science and Technology, vol. 31, no. 2021, pp. 825-841, 2021.

[18] M. Gao, H. Haichun, S. Xue et al., "Discing behavior and mechanism of cores extracted from Songke-2 well at depths below 4,500 m," International Journal of Rock Mechanics and Mining Sciences, vol. 149, Article ID 104976, 2022.

[19] L. Han, L. Wang, X. Ding, H. Wen, X. Yuan, and W. Zhang, "Similarity quantification of soil parametric data and sites using confidence ellipses," Geoscience Frontiers, vol. 13, no. 1, Article ID 101280, 2022.

[20] B. Yan, S. Che, D. D. Tannant, and F. Ren, "Application of double-yield model in numerical simulation of stability of mining filling body," Arabian Journal of Geosciences, vol. 12, no. 16, pp. 1-17, 2019.

[21] L. Han, L. Wang, W. Zhang, B. Geng, and L. Shang, "Rockhead profile simulation using a simplified generation method of conditional random field," Journal of Rock Mechanics and Geotechnical Engineering, vol. 14, 2021.

[22] Z. Tao, Y. Shu, X. Yang, Y. Peng, Q. Chen, and H. Zhang, "Physical model test study on shear strength characteristics of slope sliding surface in Nanfen open-pit mine," International Journal of Mining Science and Technology, vol. 30, no. 3, pp. 421-429, 2020.

[23] Y. Liu, F. Dai, and P. Pei, “A wing-crack extension model for tensile response of saturated rocks under coupled static-dynamic loading," International Journal of Rock Mechanics and Mining Sciences, vol. 146, Article ID 104893, 2021.

[24] Y. Liu and F. Dai, "A review of experimental and theoretical research on the deformation and failure behavior of rocks subjected to cyclic loading," Journal of Rock Mechanics and Geotechnical Engineering, vol. 13, no. 5, pp. 1203-1230, 2021.

[25] C. Wang, B. Shen, J. Chen et al., "Compression characteristics of filling gangue and simulation of mining with gangue backfilling: an experimental investigation," Geomechanics and Engineering, vol. 20, no. 6, pp. 485-495, 2020.

[26] C. Feng, L. Zhaoyuan, C. Jianqiang et al., "Research on reducing mining-induced disasters by filling in steeply inclined thick coal seams," Sustainability, vol. 11, no. 20, p. 5802, 2019.

[27] F. N. Wang, Z. B. Guo, X. B. Qiao et al., "Large deformation mechanism of thin-layered carbonaceous slate and energy coupling support technology of NPR anchor cable in Minxian Tunnel: a case study," Tunnelling and Underground Space Technology, vol. 117, Article ID 104151, 2021. 